\title{
Using Dispositions in the EdD Admissions Process: A Perceptual Approach
}

\author{
James G. Allen, EdD \\ Northern Kentucky University \\ allenj4@nku.edu \\ Mark Wasicsko, PhD \\ Northern Kentucky University \\ wasicskom1@nku.edu \\ Paul J. Wirtz, PhD \\ Northern Kentucky University \\ wirtzp1@nku.edu
}

\begin{abstract}
This article describes the theoretical basis, rationale, and pragmatic considerations for intentionally assessing specific dispositions in the admission process for educational leaders in a selective, practitioner/scholar EdD program at a regional, comprehensive university. The goal of the admissions process is to select and admit experienced leaders with the high potential to become transformational leaders who move people, organizations, and their broader communities to increasing levels of excellence. This, we believe, can be accomplished by making dispositions one of the selection criteria in the admission of candidates as well as intentionally enhancing dispositional growth throughout the program. Five areas are addressed herein: (a) defining dispositions, (b) assessing dispositions, (c) using dispositions as admission criteria, (d) preliminary findings in using the model with doctoral candidates, and (e) correlations with perceived effectiveness of doctoral candidates as leaders. The data presented validates the efficacy of using dispositional measures in program admission decisions.
\end{abstract}

KEYWORDS: assessing leader dispositions; EdD student admissions; leadership development

\section{INTRODUCTION}

Transformational educational leaders are in high demand especially now with the vacuum created by baby-boomer retirements and accelerated turnover due to increasingly stressful and demanding educational environments. However, this predicament also offers a great opportunity for leadership programs to initiate significant positive transformational change through its graduates if we recruit and admit talented future leaders, help develop them, and then assist them in growing their leadership knowledge, skills, and dispositions. One of the recruitment criteria, the authors contend, should be evidence of effective leadership dispositions.

In general, we have good research on the strategies and techniques that seem to be associated with effective leadership and yet leaders who can foster transformative change remain the outliers rather than the rule (Marzano, Waters, \& McNulty, 2005). The element that is frequently missing or underdeveloped in most leadership programs is the intentional integration of the research and practices for assessing and developing leadership dispositions that play $a$, and maybe even the, primary role in transformational leadership (Allen, Wasicsko, \& Chirichello, 2014). Most leadership programs shy away from dealing directly with dispositions due to the nature of their definition and measurement. As we shall contend, leadership dispositions are both definable and measurable, and the intentional inclusion of dispositions are necessary conditions for both selecting and preparing leaders who can foster transformational change through their efforts. This article focuses on the use of dispositional assessments in the admissions process of a practitioners' EdD program for experienced leaders.

The admissions process described below is one necessary element we employ to create a new type of practitioner-scholar doctorate that prepares leaders to bridge the gulf between the "ivory tower" and "real world." The expected outcome is leaders who can integrate and apply theory and research in schools and organizations to facilitate transformational growth. This new breed of program, aligned with the guiding principles of the Carnegie Project on the Education Doctorate (CEPD, 2018), is different because it attempts to integrate three equally important elements that are the essential ingredients for transformational practitioner-scholar-leaders: (1)
New articles in this journal are licensed under a Creative Commons Attribution 4.0 United States License.

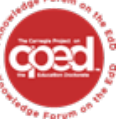

This journal is supported by the Carnegie Project on the Education Doctorate: A Knowledge Forum on the EdD (CPED) cpedinitiative.org 
knowledge of theory and research, (2) application of best practices or skills, and (3) the dispositions to lead-the human elements that inspire and magnify the first two.

\section{FRAMEWORK}

As a part of our admissions process, we ask applicants, "What is the first thing you remember about the most effective leader with whom you worked?" (Allen, Wasicsko, and Chirichello, 2014, p. 137). Typical responses include the human aspects of the leader and the types of personal relationships that were cultivated:

"She really enjoyed her work and cared about people."

"He looked for the good in each of us."

"He could get things done and make it fun."

"He believed in me."

"She challenged us."

"She saw us as unique and treated us with respect."

What differentiated the most effective leaders from the rest was that they were successful not only because of what they knew and did but because of who they were that shined through their skills and leadership abilities. And who the leaders were is a product of their humanness or what we call "dispositions."

Several theoretical models have undertaken efforts to describe and understand these "human factors." Two of the most popular models are "emotional intelligence" (Goleman, 1995; Mayer \& Salovey, 1997; Mayer, Salovey, \& Caruso, 2000; Salovey \& Mayer, 1990) and "perceptual (field) psychology" (Combs, Richards, \& Richards, 1976; Combs \& Snygg, 1949). Due to issues of parsimony, history, instrumentation, and a long (50 years + ) research history, the Combs (1974) model was adopted as a framework for embedding "dispositions" into the EdD program.

The framework used for incorporating dispositions into the admissions process is built upon the theory and research pioneered by Arthur W. Combs (1974), psychologist/educator (1935-1999). The Perceptual Dispositions Model:

drills down into the essence of the person; to the attitudes, values, beliefs, or perceptions level of the personality; to the roots of a person's actions, motivations, and interactions. Using this approach allows for a more manageable number of variables to define and measure [four in all], and more predictive value, but with the trade-off of requiring the use of more qualitative assessment measures. (Wasicsko, Wirtz, \& Resor, 2009, p. 20)

This model was chosen because it is "straightforward and intuitive, easily understood, built upon a strong theoretical and research base, and has proven qualitative measurement tools by which to assess dispositions" (Allen, Wasicsko, and Chirichello, 2014, p. 137).

Based on the research from Combs (Combs \& Snygg, 1949; Combes et al., 1969), Wasicsko (2007) categorized dispositions into four general areas that differentiate effective from ineffective leaders:

1. perception about self;

2. perceptions about other people;

3. perceptions of purpose; and

4. perceptions of one's frame of reference.
These categories are detailed and defined by Allen, Wasicsko, and Chirichello (2014) as follows:

Perception of Self, as the name implies, focuses on the personhood of the leader. Leaders who have positive perceptions of self are confident without being overbearing, identify more readily with others, can see diverse points of view, and display a positive attitude toward life and work. Because of a positive sense of self, they tend to be more selftrusting and, thus, less threatened by others; have less difficulty accepting constructive criticism; and can provide others with feedback that is more likely to be non-threatening and, thus, heard.

Leaders who have positive Perception of Others see people with whom they work as having the capacity to face up to challenges and be successful when given the opportunity and resources. They demonstrate a belief in others' ability to find adequate solutions to events in their own lives; display a general belief that all people are valuable, able, and worthy of respect; share responsibilities with others; and share or give away credit for accomplishments.

Leaders who have high Perception of Purpose have goals that extend beyond the immediate to broad implications and contexts. They tend to see the big picture and yet have an uncanny ability to be present in the moment. They are committed to life-long learning and mentoring; treat everyone equitably and fairly; avoid being sidetracked by trivia or petty issues; and see work in the larger context of life. They realize that what they do as leaders is more than a mere job but less than a life.

Finally, leaders who are people-oriented have a Frame of Reference that recognizes that people, with all their human strengths and frailties, are the valuable human resources through which goals get met rather than cogs in a complex mechanical machine. They understand that, while order, management, mechanics, and details of things and events are necessary, long-term success must be concerned with the human aspects of affairs - the attitudes, feelings, beliefs, and welfare of persons. They understand the importance of maintaining positive relationships with colleagues, and they focus on the human dimensions rather than, or at least in addition to, the "things" associated with the work. (pp. 137138)

These dispositions, the authors contend, are a priori elements that, when present in a leader, set the stage for greater transformational change and growth in individuals and organizations. However, they develop slowly and incrementally over the course of a lifetime and are not, in general, quickly, easily, or drastically changed over the relatively short timeframe of a leadership program, hence the need to select for dispositions at admissions and then intentionality plan for and facilitate their growth throughout the leadership program.

\section{ASSESSING DISPOSITIONS}

The Perceptual Dispositional Model was chosen because it is straightforward, easily understood by students and faculty, and is built upon a strong theoretical and research base. Also, it has a readily available, research-based assessment tool that, when used by skilled raters, provides highly valid information that can be used for predictive purposes such as in an admissions process.

Studies by Combs and others used one or more of the perceptual/dispositional scales in Figure 1 with highly skilled raters to assess subject dispositions. In these studies, the scales were used 
to assess subjects' dispositions in direct observations, interviews, and written vignettes (called Human Relations Incidents) about teaching or helping experiences. In addition to finding significance in differentiating effective from ineffective teachers, a high positive correlation was found among the perceptual factors. For example, a person scoring high on ability to identify with diverse individuals tended to be people rather than thing oriented. This same relationship existed among the other scales, and in virtually no instance did a person rate very high on one factor and very low on another. This led to the hypothesis that in the highly effective person all the traits are integrated and inter-related and, for the sake of parsimony, allows for the use of fewer dimensions for assessing a person's dispositions without sacrificing validity. This also has implications for developing curricular experiences to positively affect dispositions: experiences that facilitate positive change in any one area may have a corresponding effect on the others.

\begin{tabular}{|c|c|c|c|c|c|c|c|c|c|c|c|c|}
\hline PERCEPTUAL ORIENTATION & 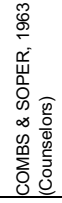 & 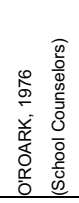 & 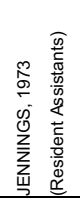 & 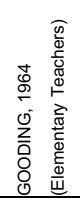 & 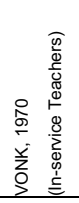 & 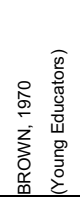 & 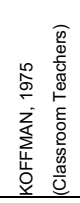 & 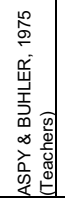 & 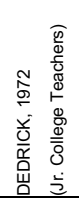 & 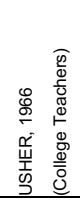 & 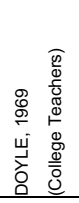 & 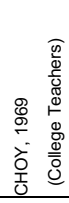 \\
\hline \multicolumn{13}{|l|}{ PERCEPTION OF SELF } \\
\hline IDENTIFIED-UNIDENTIFIED & $\mathrm{s}$ & & $\mathrm{s}$ & $\mathrm{s}$ & $\mathrm{s}$ & $\mathrm{s}$ & $\mathrm{s}$ & $\mathrm{s}$ & $\mathrm{s}$ & ns & $\mathrm{s}$ & \\
\hline ABLE-UNABLE & $\mathrm{s}$ & & $\mathrm{s}$ & $\mathrm{s}$ & & & & $\mathrm{s}$ & $\mathrm{s}$ & ns & & \\
\hline POSITIVE-NEGATIVE & & & & & & $\mathrm{s}$ & & $s$ & & & $\mathrm{~s}$ & $\mathrm{~s}$ \\
\hline \multicolumn{13}{|l|}{ PERCEPTION OF OTHERS } \\
\hline ABLE-UNABLE & $\mathrm{s}$ & $\mathrm{s}$ & $\mathrm{s}$ & $\mathrm{s}$ & & & $\mathrm{s}$ & & $\mathrm{s}$ & $\mathrm{s}$ & & \\
\hline DEPENDABLE-UNDEPENDABLE & $\mathrm{s}$ & & & $\mathrm{s}$ & & & $\mathrm{s}$ & & & $s$ & & \\
\hline WORTHY-UNWORTHY & $\mathrm{s}$ & & $\mathrm{s}$ & $\mathrm{s}$ & & $\mathrm{s}$ & $\mathrm{s}$ & & $\mathrm{s}$ & $\mathrm{s}$ & & \\
\hline \multicolumn{13}{|l|}{ PERCEPTION OF PURPOSE } \\
\hline LARGER-SMALLER & $\mathrm{s}$ & & & $\mathrm{s}$ & $\mathrm{s}$ & & & & & & & \\
\hline FREEING-CONTROLLING & $\mathrm{s}$ & & $\mathrm{s}$ & $\mathrm{s}$ & $\mathrm{s}$ & $\mathrm{s}$ & & & $\mathrm{s}$ & ns & & \\
\hline REVEALING-CONCEALING & $\mathrm{s}$ & $\mathrm{s}$ & $s$ & $\mathrm{~s}$ & $\mathrm{~s}$ & $s$ & & & & ns & & \\
\hline \multicolumn{13}{|l|}{ FRAME OF REFERENCE } \\
\hline PEOPLE-THINGS & $\mathrm{s}$ & & & $\mathrm{s}$ & & & & & & & & \\
\hline INTERNAL-EXTERNAL & $\mathrm{s}$ & $\mathrm{s}$ & $\mathrm{s}$ & $\mathrm{s}$ & & & & & $\mathrm{s}$ & & & \\
\hline $\begin{array}{l}\text { OPENNESS-CLOSEDNESS } \\
\text { (TO EXPERIENCE) }\end{array}$ & & $s$ & & & s & & & & & & s & \\
\hline \multicolumn{13}{|l|}{$\begin{array}{l}\mathrm{S}=\text { Significant } \\
\mathrm{ns}=\text { Not significant } \\
\text { Blank = Not tested } \\
{ }^{*} \text { Definitions used in text }\end{array}$} \\
\hline
\end{tabular}

Figure 1. Perceptual (dispositional) Studies: Helper Effectiveness Research from the Florida Studies in the Helping Professions (Combs et al., 1969).

Wasicsko (1977b) studied the teachability of the 12 perceptual factors and found that four factors were more rapidly acquired in training sessions. The four factors, one in each area, were:

1. Perceptions of self as identified with a broad range of people rather than unidentified.

2. Perceptions of others as able to deal with the problems they face rather than unable.

3. Perceptions of purpose in terms of larger implications rather than smaller immediate outcomes.

4. A frame of reference that focuses on people concerns rather than things.
This subsequently led to the development of self-instructional training materials for the four perceptual/dispositional factors (Wasicsko, 1977a, 2005). These four perceptual factors were chosen as the scales for the dispositions construct in the Perceptual Dispositions Model (Figure 2). Each scale is made up of a pair of definitions on a seven-point Likert Scale with the effective dispositions on one end (7) and those of ineffective dispositions on the other (1).

Before using the scales, systematic training and acceptable proficiency must be demonstrated. Self-instructional materials and a proficiency test are available for free on the website of the National Network for the Study of Educator Dispositions (NNSED, 2018) at www.educatordispositions.org. 


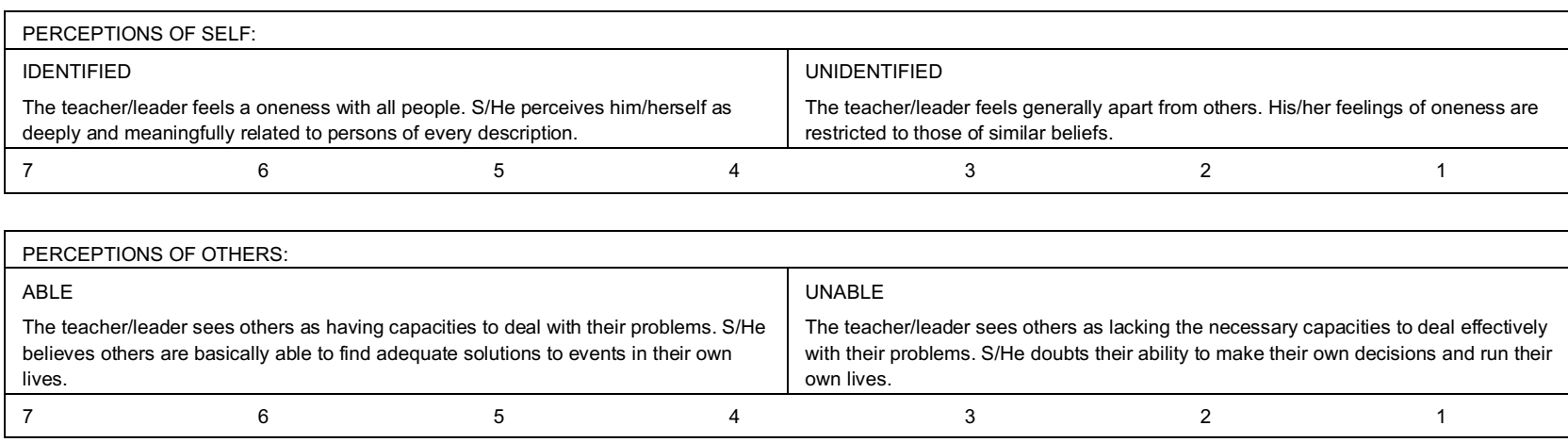

\begin{tabular}{|c|c|c|}
\hline \multicolumn{3}{|c|}{ PERCEPTIONS OF PURPOSE: } \\
\hline & & SMALLER \\
\hline & $\begin{array}{l}\text { events in a broad perspective. His/her goals extend beyond } \\
\text { plications and contexts. }\end{array}$ & $\begin{array}{l}\text { The teacher/leader views events in a narrow perspective. His/her purposes focus on } \\
\text { immediate and specific goals. }\end{array}$ \\
\hline 7 & 6 & 2 \\
\hline
\end{tabular}

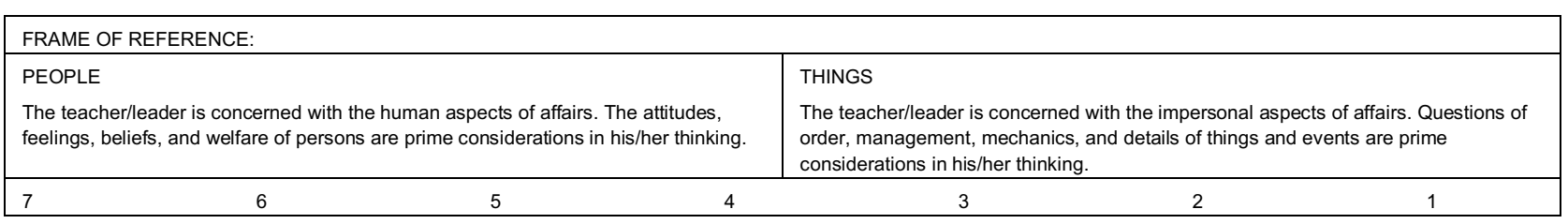

Figure 2. Dispositional Rating Scales.

\section{DISPOSITIONS AS ADMISSION CRITERIA}

As one element of the comprehensive admissions process in our EdD program, we intentionally assess dispositions of applicants with the goal of selecting and admitting leaders with the high potential to become transformational leaders who can move people, organizations, and their broader communities to increasing levels of success. Each admitted candidate becomes a collaborative member of a cohort that functions as a learning and support system of students (we call them "learning associates") who share responsibility for all the members' success. Since the program graduates are prepared to be community leaders as well as leaders in their organization, their dispositions are a critical consideration. As shall be seen in the data collected and described below, our admissions process successfully identifies and selects candidates possessing the desired qualities.

The admissions process applies the perceptual disposition model with a multi-step procedure. The consideration of the candidates' dispositional qualities begins with reviewing the written application materials then a face-to-face group interview, and, finally, through a review of an on-demand written essay that each applicant is required to compose on the day of the interview. In each instance, the Dispositional Rating Scales (Figure 2) are applied by trained faculty assessors to determine if the desired dispositions are evident. Before a candidate is offered admission, the faculty members review the entire admissions portfolio to determine if the person has provided evidence of four elements: civic/organizational ambition, leadership trajectory, timing, and the focus of this manuscript-fit (dispositions).

\section{Application Materials}

Within the written application materials, each candidate submits a leadership letter describing her/his experiences and accomplishments. In the letter, applicants describe the reasons for applying to the EdD program including their leadership experiences, style, and philosophy; personal and professional goals; and how they imagine they might use the doctoral studies to further their goals and aspirations. In addition to the letter, candidates submit a leadership situation essay where they describe a personally meaningful event in which they served in a formal or informal leadership role. They are asked to address each of the following questions:

1. Describe the situation as it occurred at the time.

2. What did you do in that particular situation?

3. How did you feel about the situation at the time you were experiencing it?

4. How do you feel about the situation now?

5. What would you change, if anything?

These essays are very telling and cue our trained faculty assessors as to the individual's perception of self, others, purpose and frame of reference. Faculty serving on the admissions review committee are trained and certified in using the Dispositional Rating Scales have interrater reliability over $80 \%$.

Applicants deemed to have met program admissions criteria including the desired dispositions on their written admissions materials are invited for an interview. A structured group interview format has been deliberately selected for this part of the process. 


\section{Group Admissions Interview}

A group interview strategy was designed to elicit more information about applicant dispositions. The group interview typically includes four to five applicants and two to three faculty members. An attempt is made to have at least one more applicant interviewee than faculty interviewer. This approach is used because we are interested not only in the applicants' answers to the questions but how they listen to and interact with each other. As described briefly above, our program employs a cohort-based model in which all members are both learners and instructors, hence the importance of interpersonal skills. All responses and interactions are assessed by faculty for the content and presentation of their answers as well as an assessment of their dispositions using the Dispositional Rating Scales.

Following are sample questions that would be asked of each applicant in turn with the following question rotating to the next applicant. A brief description/rationale regarding the dispositions the question is meant to elicit is included.

- What is the first characteristic that comes to mind when you think of the best leader with whom you have worked? Why? (Dispositions: e.g., Applicant chooses a characteristic that focuses on people rather than things; articulates how that characteristic made the leader successful; sees the big picture, distributes authority, responsibility, and rewards; positive and up-beat.)

- Give an example of either a formal or informal successful leadership experience in which you have been involved? (Dispositions: The applicant is able to clearly describe a successful leadership experience in which s/he was involved. Applicant is enthusiastic about the event, sees the larger implications, realizes that it was a collaborative endeavor, shares accomplishments.)

- What are the most important characteristics you possess that will allow you to be successful in a doctoral program? (Dispositions: Applicant focuses on characteristics that are people oriented rather than thing oriented; demonstrates a desire and ability to build positive relationships with students, faculty, and parents; focuses on helping students be successful.)

- What has been the most meaningful leadership experience you have had? (Dispositions: Applicant focuses on larger implications, involved others and improved their conditions, collaborative.)

- What will you do differently to meet the demands of a doctoral program and still have sufficient time and energy to meet your occupational and other obligations? (Dispositions: Realistic notions about what it takes to be successful, calls upon others for assistance and support.)

- Describe a situation in which you worked successfully with someone who is racially or culturally different than you. (Dispositions: Describes diversity experience with good understanding that everyone is an individual, everyone has a voice, everyone needs to be heard, everyone is important. Identifies with others and is a people person.)

- Describe a situation in which you were not successful. What happened? What could you have done differently to change the outcome? (Dispositions: Candidate is able to describe the situation clearly including what he/she did wrong and offers ideas on what could have been done differently to change the outcome. Sees the bigger picture, larger viewpoint, and the lesson learned.)

- What is the most important leadership strategy you would use to increase "buy-in" and positive outcomes? (Dispositions: Sharing responsibility and rewards, clearly articulates the outcomes and encourages others to help develop goals and outcomes.)

- Give us an example of a time you used humor successfully, either to build rapport or diffuse a difficult situation. (Dispositions: Not taking oneself too seriously-dispositions toward self, relationships with people.)

At the conclusion of the interview, applicants complete an ondemand writing exercise in which they respond to questions relating to a published article on leadership. In addition to serving as another measure of dispositions, applicants are assessed on how well they organize and support their thoughts.

\section{PRELIMINARY FINDINGS}

As part of ongoing program assessment, development, and renewal, faculty review candidate data on multiple measures including those collected during the admissions process. To validate faculty assessment of candidates' dispositions from admissions, we compare these data with external reviewers' assessments of all of our learning associates as a part of a $360^{\circ}$ evaluation process. Our preliminary findings indicate that the admissions process is successfully admitting for the desired leadership dispositions.

During the first semester of the program, our learning associates engage in a $360^{\circ}$ evaluation process in order to help them continue to grow as leaders. The Individual Leadership SelfAssessment (ILSA) ${ }^{1}$, the instrument used in this process (Allen et al., 2014), measures 34 leadership traits/characteristics and 20 dispositions. During their first semester in the program, learning associates complete the ILSA as a self-assessment of their leadership traits and dispositions. Additionally, they identify at least ten critical friends (co-workers) who complete the survey instrument about their leadership capacity. During the second year of the program, fellow learning associates (cohort members) complete the ILSA for each member of the cohort. ILSA was designed to collect authentic data from a variety of sources (self, critical friends, and fellow learning associates), to serve as a self-assessment baseline from which growth plans are designed, and to measure growth over time. This process is based on four assumptions: feedback is important for personal and professional growth; most organizations

1 The ILSA now has a free, online version available for use by any leadership program that can be found at www.leaderdispositions.org. 
fail to provide authentic feedback; research has shown that $360^{\circ}$ feedback can lead to improved performance; and there is frequently a gap between a leader's self-perception and how others see her/him.

Students receive aggregated feedback on all 54 items comparing their self-assessment with the scores from their critical friends during the first semester in the program. During their second year in the program, they also receive the feedback from their fellow learning associates. These data are used by learning associates to create growth plans and by program faculty for course and program development purposes and to validate our own assessment of candidates' dispositions from admission.

For this article, we are reporting here only the data from the twenty dispositional items (Figure 3 ) from a sample of 74 of our learning associates and 573 of their critical friends. As noted earlier, admitted applicants must receive a score of a 5,6 , or 7 on each Perceptual Rating Scale on the written application materials, the face-to-face group interview, and a written essay. Each scale is made up of a pair of definitions on a seven-point Likert Scale with the effective dispositions on one end (7) and those of ineffective dispositions on the other (1). Those candidates scoring below a 5 in any one or more areas are typically not admitted to the program. As part of ongoing program evaluation, we ask ourselves each year if our assessment of candidates' dispositions at admissions is an accurate or authentic portrait of who our learning associates are as learners and leaders. The $360^{\circ}$ data is one measure we use to validate our admissions assessment.

\begin{tabular}{|c|c|c|c|c|c|c|c|}
\hline Perceptions of Self & 1 & 2 & 3 & 4 & 5 & 6 & 7 \\
\hline \multicolumn{8}{|l|}{ Identifies positively with others even those who are different than s/he is. } \\
\hline \multicolumn{8}{|l|}{ Always try to see the other person's point of view. } \\
\hline \multicolumn{8}{|l|}{ Displays a generally positive attitude toward life and work. } \\
\hline \multicolumn{8}{|l|}{ Is accepting of others whose ideas and opinions differ from self. } \\
\hline \multicolumn{8}{|l|}{ Accepts constructive criticism. } \\
\hline Perceptions of Others & 1 & 2 & 3 & 4 & 5 & 6 & 7 \\
\hline \multicolumn{8}{|l|}{ Displays a general belief that all people are valuable, able, and worthy. } \\
\hline \multicolumn{8}{|l|}{ Collaborates positively with others. } \\
\hline \multicolumn{8}{|l|}{ Shares responsibility with others. } \\
\hline \multicolumn{8}{|l|}{ Finds positive things about almost everyone s/he meets. } \\
\hline \multicolumn{8}{|l|}{ Shares credit for accomplishments with others. } \\
\hline Perceptions of Purpose & 1 & 2 & 3 & 4 & 5 & 6 & 7 \\
\hline \multicolumn{8}{|l|}{ Sees the big picture in most situations. } \\
\hline \multicolumn{8}{|l|}{ Treats everyone equitably and fairly. } \\
\hline \multicolumn{8}{|l|}{ Sees work in the larger context of a person's life. } \\
\hline \multicolumn{8}{|l|}{ Avoids being sidetracked by trivia or petty issues. } \\
\hline \multicolumn{8}{|l|}{ Is committed to life-long learning for self and others. } \\
\hline Frame of Reference & 1 & 2 & 3 & 4 & 5 & 6 & 7 \\
\hline \multicolumn{8}{|l|}{ Primary focus is on the success of the people with whom s/he interacts. } \\
\hline \multicolumn{8}{|l|}{ Balances work and life. } \\
\hline \multicolumn{8}{|l|}{ Builds and maintains positive relationships with colleagues. } \\
\hline \multicolumn{8}{|l|}{ Builds and maintains positive relationships with clients. } \\
\hline Focuses on the human aspects (rather than things) in most situations. & & & & & & & \\
\hline
\end{tabular}

Figure 3. Dispositional Items from the Individual Leadership Self-Assessment (ILSA). 
As noted earlier, learning associates who are admitted to our program are rated highly (typically scoring in the 5-7 range) on dispositional elements by our trained faculty assessors. We compare here, learning associates self-assessments $(\mathrm{N}=74)$ with the corresponding data from their critical friends $(\mathrm{N}=573)$, and their fellow learning associates $(\mathrm{N}=74)$.

Within the first category, Perceptions of Self (Figure 4), mean ratings range from 4.88 on "Accepts constructive criticism" (SelfAssessment rating) to 6.14 on "Displays a generally positive attitude toward life and work" (Critical Friends' rating). According to the
Critical Friends and Fellow Learning Associates, our learning associates' scores fall within the effective dispositions range for Perceptions of Self as identified with a broad range of people rather than unidentified. All but one of the Self-Assessment scores falls within this same range. Effective leaders' scores on these questions typically range from 5 to 7 which represents a oneness with all people as opposed to feeling generally apart from others. Leaders within the 5 to 7 range are also perceived as deeply and meaningfully related to persons of every description as opposed to his/her feelings of oneness restricted to those of similar beliefs (identified vs. unidentified).

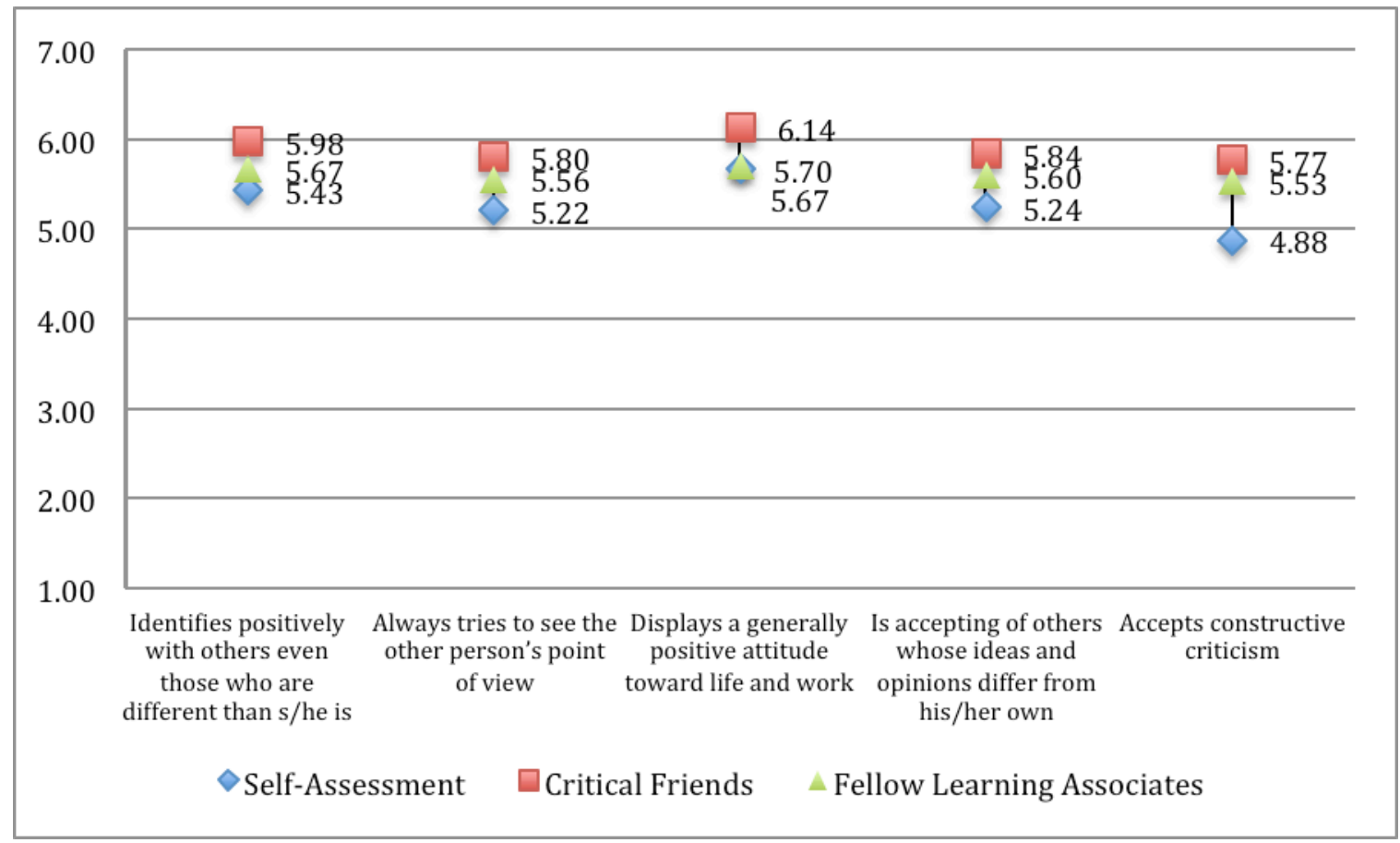

Figure 4. Perceptions of Self. Self-Assessment $N=74$, Critical Friends $N=573$, Fellow Learning Associates $N=74$.

Within the second category, Perceptions of Others (Figure 5), a similar pattern occurs and mean ratings range from 5.28 on "Finds positive things about almost everyone s/he meets" (Self-Assessment rating) to 6.23 on "Displays a general belief that all people are valuable, able, and worthy" (Critical Friends rating). According to these data, our learning associates' scores on all items fall within the effective dispositions range for Perceptions of Others as able to deal with the problems they face rather than unable. Effective leaders' scores on these questions typically range from 5 to 7 which represents the ability to see others as having capacities to deal with their problems. Leaders within the 5 to 7 range are also perceived to believe others are basically able to find adequate solutions to events in their own lives (able vs. unable). 


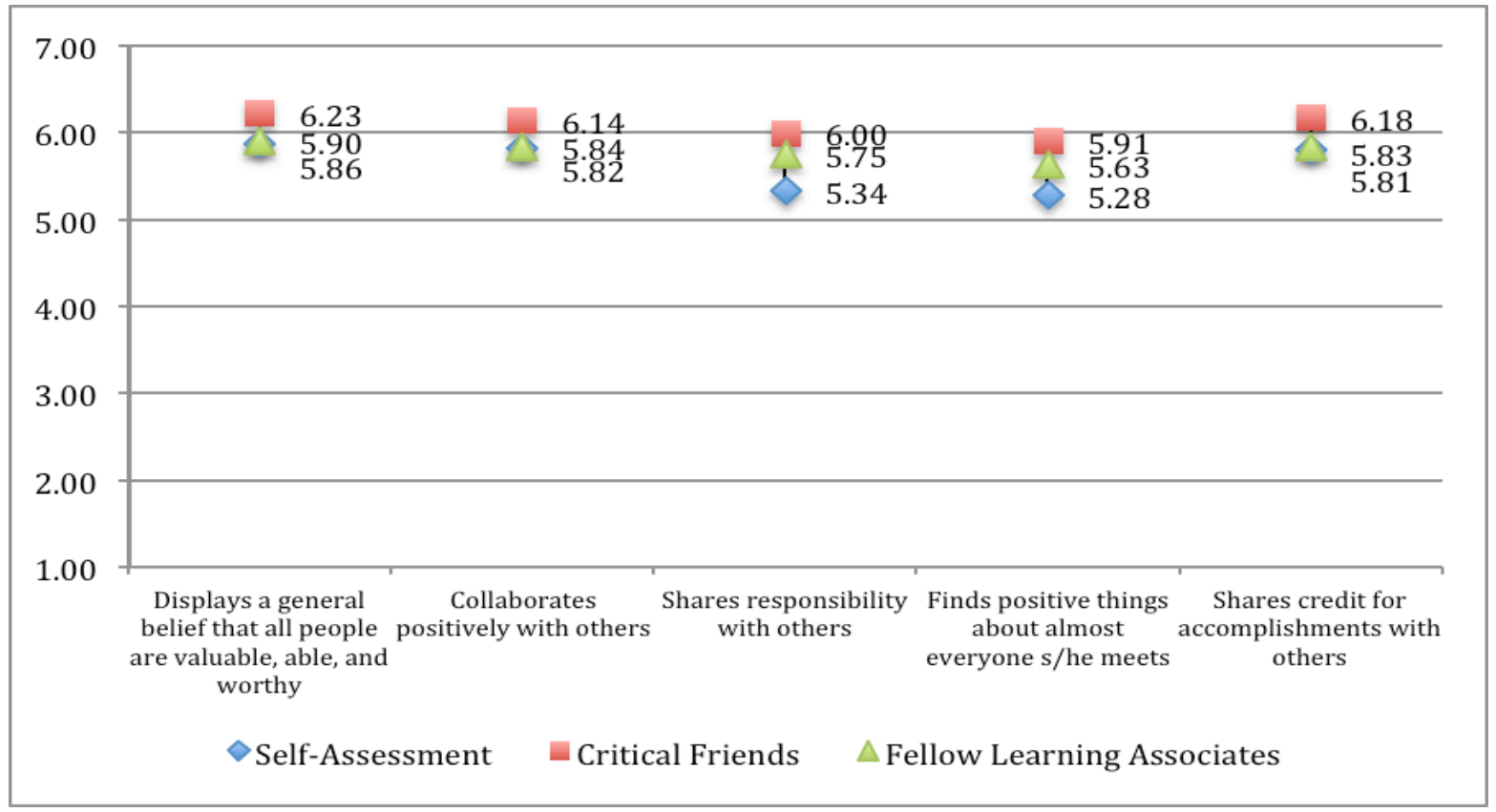

Figure 5. Perceptions of Others. Self-Assessment $N=74$, Critical Friends $N=573$, Fellow Learning Associates $N=74$.

Within the third category, Perceptions of Purpose (Figure 6), mean ratings range from 4.73 on "Avoids being sidetracked by trivia or petty issues" (Self-Assessment rating) to 6.52 on "Is committed to life-long learning for self and others" (Critical Friends rating).

According to all but one of these data points, our learning associates' scores fall within the effective dispositions range for Perceptions of
Purpose in terms of larger implications rather than smaller immediate outcomes. Effective leaders' scores on these questions typically range from 5 to 7 which represents the ability to view events in a broad perspective. Leaders within the 5 to 7 range are also perceived to believe his/her goals extend beyond the immediate to larger implications and contexts (larger vs. smaller).

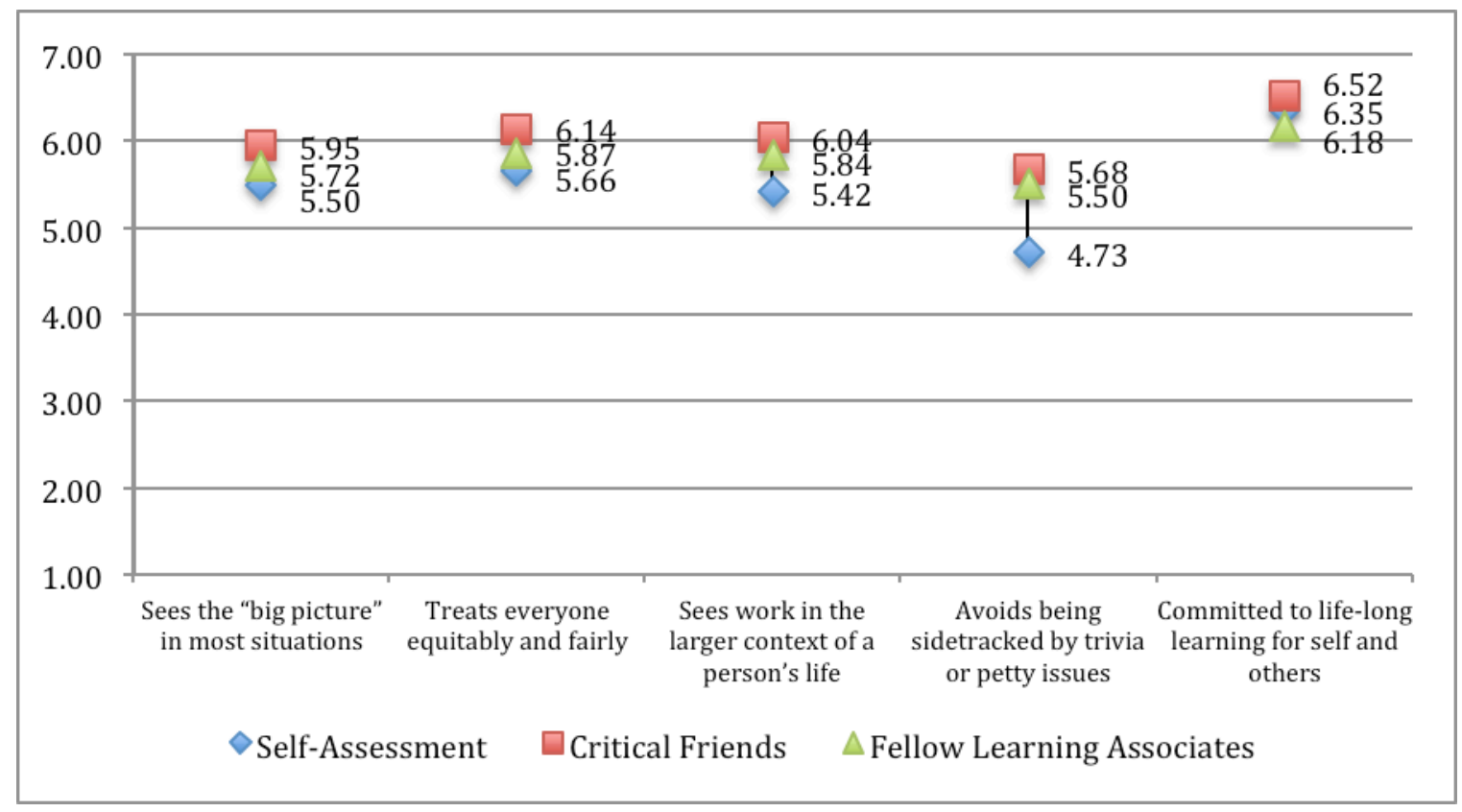

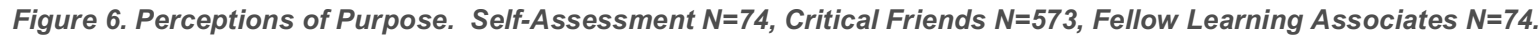


Within the fourth and final category, Frame of Reference (Figure 7), mean ratings range from 4.42 on "Balances work and life" (SelfAssessment rating) to 6.19 on "Builds/maintains positive relationships with students/clients" (Critical Friends rating). According to the Critical Friends and Fellow Learning Associates, our learning associates' scores fall within the effective dispositions range for Frame of Reference in terms of a focus on people concerns rather than things. Effective leaders' scores on these questions typically range from 5 to 7 which represents leaders' concerns with the human aspects of affairs. Leaders within the 5 to 7 range are concerned with the attitudes, feelings, beliefs, and welfare of persons which are prime considerations in her/his thinking (people vs. things).

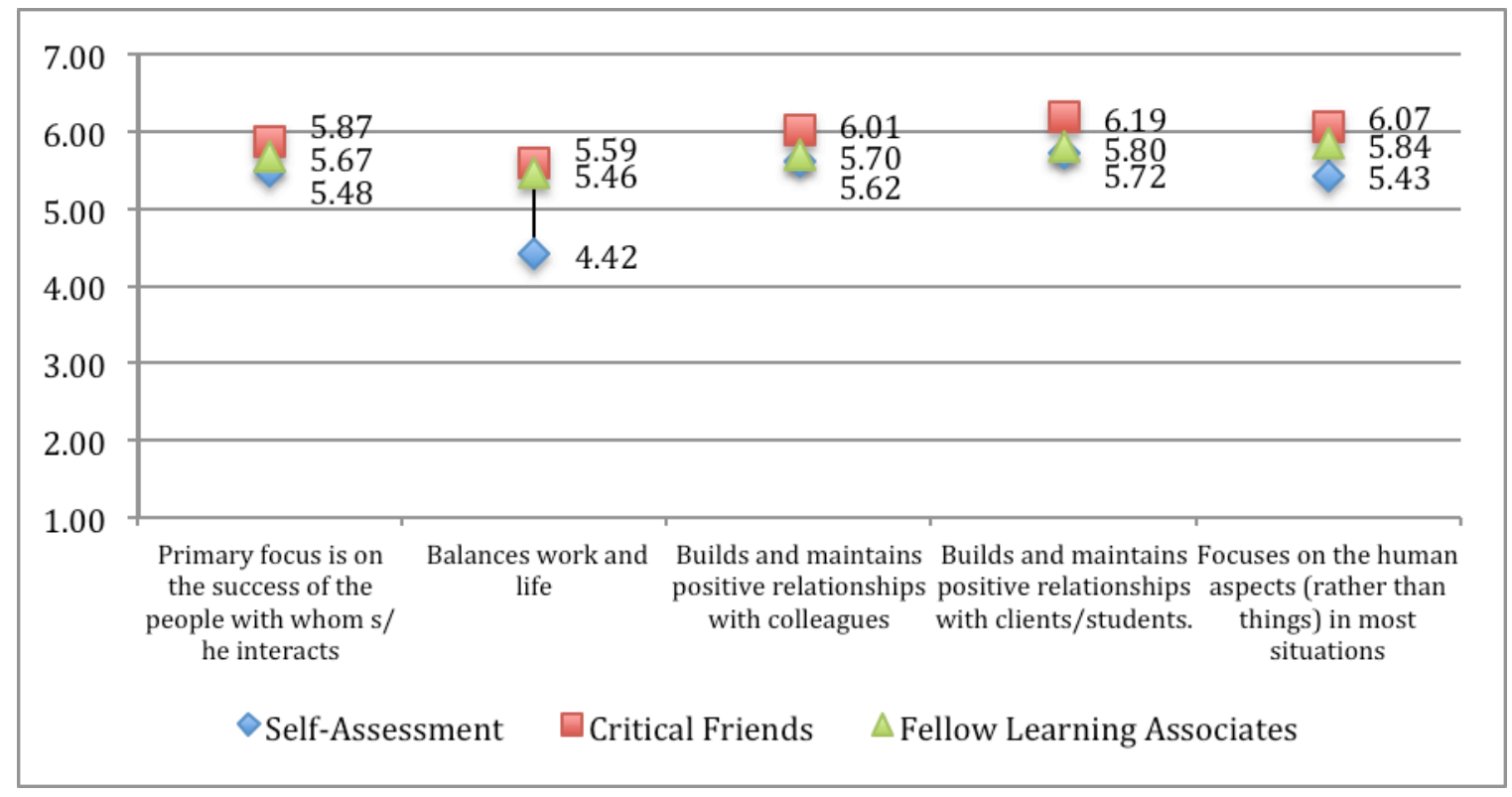

Figure 7. Frame of Reference. Self-Assessment $N=74$, Critical Friends $\mathbf{N}=573$, Fellow Learning Associates $N=74$.

As outlined earlier, learning associates who are admitted to our program are rated highly on dispositional elements by our trained faculty assessors. Additionally, our Learning Associates selfassessment ratings correlate positively with the scores from their critical friends and their fellow learning associates as outlined here. In fact, all twenty items within the four perceptual/dispositional factors rated by critical friends and fellow learning associates fall within the effective dispositions range.

\section{CONCLUSIONS}

After ten years of participating with learning associates in the program, we have seen that the dispositional screening process has been effective in selecting those candidates who demonstrate our desired leadership dispositions. Furthermore, we have been able to validate our assessment of their dispositions by correlating entry dispositional assessments with those of our learning associates' critical friends and their fellow learning associates. In addition to these data, we have observed candidates who commit themselves deeply to civic engagement and have made recognized contributions to their communities through collaborative initiatives and support for nonprofit organizations and other agencies. A required element of the program is that each candidate must select and implement an action research project that impacts their organization or community. Our graduates have excelled in this area and have been rewarded with regional and statewide recognition for their competence and commitments.
The essential role of assessing dispositions in the admissions process is to admit candidates with greater potential to foster transformational growth in their organizations and communities; And then, in a program designed specifically to grow good managers into transformational leaders, provide experiences that increase the persons' leadership knowledge, skills, and dispositions. Assessing applicants' dispositions throughout the admissions process utilizing the Perceptual Dispositions Model has proved to be an effective method for identifying successful participants who complete the program and, in most cases, move to positions of greater influence.

In this article, we described the theoretical basis, rationale, and pragmatic considerations for intentionally assessing specific dispositions in the admission process for educational leaders in a selective, practitioner/scholar EdD program at a regional, comprehensive university. The goal of our admissions process is to select and admit experienced leaders with a high potential to become transformational leaders who move people, organizations, and their broader communities to increasing levels of excellence. This, we believe, has been accomplished by making dispositions one of the selection criteria in the admission of candidates as well as intentionally enhancing dispositional growth throughout the program. 


\section{REFERENCES}

Allen, J. G., Wasicsko, M. M., \& Chirichello, M. (2014). The missing link: Teaching the dispositions to lead. International Journal of Educational Leadership Preparation, 8(1), 135-147.

Aspy, D. N., \& Buhler, K. (1975). The effect of teachers' inferred self-concept upon student achievement. Journal of Education Research, 47, 386-389.

Brown, R. G. (1970). A study of the perceptual organization of elementary and secondary outstanding young educators (Doctoral dissertation). Retrieved from ProQuest Dissertations \& Theses Global. (Order No. 7124412).

Carnegie Project on the Education Doctorate. (2018). Retrieved from https://www.cpedinitiative.org/

Choy, C. (1969). The relationship of college teacher effectiveness to conceptual system and perceptual orientation (Doctoral dissertation). Retrieved from ProQuest Dissertations \& Theses Global. (Order No. 6919212).

Combs, A. W. (1974). Humanistic goals of education. In I. D. Welch, F. Richards, \& A. C. Richards (Eds.), Educational accountability: A humanistic perspective. (pp. 124-131). San Francisco, CA: Shields.

Combs, A. W., Richards, A. C., \& Richards, F. (1976). Perceptual psychology: A humanistic approach to the study of persons. New York, NY: Harper \& Row.

Combs, A. W., \& Snygg, G. (1949). Individual behavior: A perceptual approach to behavior. New York, NY: Harper \& Row.

Combs, A. W. \& Soper, D. W. (1963). The self, its derivate terms and research. Journal of Individual Psychology, 14, 64-67.

Combs, A. W., Soper, D. W., Gooding, C. T., Benton, J. A., Dickman, J. F., \& Usher, R. H. (1969). Florida studies in the helping professions. Social Science Monograph \#37. Gainsville, FL. University of Florida Press. Retrieved from http://fieldpsychtrust.org/newsite/wpcontent/uploads/2013/09/Florida_Studies.pdf

Dedrick, C. V. (1972). The relationship between perceptual characteristics and effective teaching at the junior college level (Doctoral dissertation). Retrieved from ProQuest Dissertations \& Theses Global. (Order No. 7300550).

Doyle, E. J. (1969). The relationship between college teaching effectiveness and inferred characteristics of the adequate personality (Doctoral dissertation). Retrieved from ProQuest Dissertations \& Theses Global. (Order No. 7007121)

Goleman, D. (1995). Emotional intelligence. New York, NY: Bantam Books.

Gooding, C. T. (1964). An observational analysis of perceptual organization of effective teachers (Doctoral dissertation). Retrieved from ProQuest Dissertations \& Theses Global. (Order No. 6505983).

Jennings, G. D. (1973). The relationship between perceptual characteristics and effective advising of university housing para-professional resident assistants. (Unpublished doctoral dissertation). University of Florida, Gainesville, Florida.

Koffman, R.G. (1975). A comparison of the perceptual organization of outstanding and randomly selected teachers in 'open' and traditional classrooms. (Doctoral dissertation). Retrieved from ProQuest Dissertations \& Theses Global. (Order No. 7516570)

National Network for the Study of Educator Dispositions. (2018). Retrieved from

https://inside.nku.edu/content/inside/coehs/centers/educatordispositions. html.html

Marzano, R. J., Waters, T., \& McNulty, B. A. (2005). School leadership that works: from research to results. Aurora, CO: Mid-Continent Research for Education and Learning.

Mayer, J. D. \& Salovey, P. (1997). What is emotional intelligence? In P. Salovey \& D. Sluyter (Eds.), Emotional development and emotional intelligence: Implications for educators (pp. 3-31). New York, NY: Basic Books.

Mayer, J. D., Salovey, P., \& Caruso, D. (2000). Models of emotional intelligence. In R. J. Sternberg (Ed.), The handbook of intelligence (pp. 396-420). New York, NY: Cambridge University Press.

O'Roark, A. (1976). A comparison of perceptual characteristics of elected legislators and public school counselors identified as most and least effective (Doctoral dissertation). Retrieved from ProQuest Dissertations \& Theses Global. (Order No. 7516431)
Richards, A. C. (Ed.) (2010). Matters of consequence: Selected writings of Arthur W. Combs, PhD. Carrollton, GA: A Field Psych Trust Publication.

Salovey, P. \& Mayer, J. D. (1990). Emotional intelligence. Imagination, Cognition, and Personality, 2, 185-211.

Usher, R. H. (1966). The relationship of perceptions of self, others, and the helping task to certain measures of college faculty effectiveness (Doctoral dissertation). Retrieved from ProQuest Dissertations \& Theses Global. (Order No. 6713167).

Vonk, H. G. (1970). The relationship of teacher effectiveness to perception of self and teaching purposes (Unpublished doctoral dissertation). University of Florida, Gainesville, Florida.

Wasicsko, M. M. (1977a). A research based teacher selection instrument. Retrieved from ERIC database. (ED193193)

Wasicsko, M. M. (1977b). Improving teacher selection using perceptual inference in the teacher selection process. Retrieved from ERIC database. (ED193195)

Wasicsko, M.M. (2005). Assessing educator dispositions: A perceptual approach. Retrieved from the National Network for the Study of Educator Dispositions website: http://www.educatordispositions.org

Wasicsko, M. (2007). Defining meaning and applying dispositions in teacher education programs: Sixth annual symposium on educator dispositions. Highland Heights, KY: Author.

Wasicsko, M., Wirtz, P. \& Resor, C. (2009). Using dispositions in the teacher admissions process. SRATE Journal 18(2), 19-26. 